fractionated before use. The acetic acid and cresol were chemically pure grade but were not further purified. The benzyl alcohol was fractionated. It had a boiling-point of about $202^{\circ}$ (uncorrected). The aromatic compounds were tested for optical activity,

The divergence in the results obtained with the benzyl alcohol is doubtless due to the decomposition of a part of the proteid by the heating necessary to bring it into solution. The sample giving the lower reading was purposely kept at a high temperature considerably longer than the other to see if the rotation would be markedly changed. Doubtless the other determinations are also affected with some error due to the same cause, although this was guarded against as far as was practicable.

The fact that gliadin is soluble in phenol would seem to render possible an approximate determination of its molecular weight by the freezing-point method. Since it is also soluble in boiling 70 per cent. propyl alcohol, a determination by the boiling-point method might be made since G. N. Lewis has shown ${ }^{1}$ that Raoult's law regarding the elevation of the boiling-point can be applied to a binary solvent whose vapor has the same percentage composition as the liquid. The presence of traces of moisture would affect the results by the latter method much less, although gliadin is doubtless more or less altered by continued warming with any solvent containing water.

An attempt has been made to estimate the gliadin present in flour by digestion with phenol and polarization of the filtered extract. The results obtained seem to indicate that a quite complete extraction of the gliadin is effected. It is possible, however, that more or less glutenin also dissolves in the phenol. The chief difficulty encountered is in the filtration of the mixtures.

[CONTRIBUTION FROM THE U. S. DEPARTMENT OF AGRICULTURE, BUREAU of Chemistry. Sent by H. W. WIIEY.]

\title{
THE SEPARATION OF PROTEOSES AND PEPTONES FROM THE SIMPLER AMINO BODIES.
}

\author{
BY W. D. BIgELOW AND F. C. Cook.
}

Received June 30 , Ig06.

OF THE methods that have been employed during recent years for the separation of proteoses and peptones from the simpler 1 This Journal, 28, 766 . 
amino bodies, the following methods have been used most commonly.

First, Stutzer's method ${ }^{1}$ by means of precipitation with phosphotungstic acid.

Second, Mallet's method ${ }^{2}$ by precipitation with phosphotungstic acid in hot solutions.

Third, Allen and Searle's method ${ }^{3}$ by precipitation with bromine.

Fourth, Schjerning's method by precipitation with a tannin salt solution.

It was believed by Stutzer that the method proposed by him separated peptones completely from all of the simpler amino bodies. Since that time it has been shown repeatedly that phosphotungstic acid precipitates some of the meat bases and that the reagent is not suitable for the purpose for which it was first suggested.

The bromine method of Allen and Searle ${ }^{5}$ has been shown to be utterly untrustworthy. It decomposes both proteids and meat bases with the liberation of nitrogen. It has been shown by the writers ${ }^{b}$ that bromine does not precipitate all of the proteid bodies present, that the amount precipitated under varying conditions is not constant, and that it is possible to so fix the conditions that relative amounts can be secured. It is true that the results are greatly improved by forming the bromine precipitate in the filtrate from the proteoses precipitated by zinc sulphate, the filtrate being diluted with an equal volume of water before precipitation with bromine. Even then, however, the results obtained by the method are far from satisfactory in the presence of a considerable amount of simple amino bodies.

In previous work ${ }^{7}$ the writers found the tannin salt method of Schjerning to have some advantages in this separation. Our work with this method, however, has indicated that slight changes of conditions produced marked influences on the results, and it seemed important to study the method with a view to determining whether it were not possible to so fix conditions as to obtain re-

${ }^{1} \mathrm{Z}$. anal. Chem. 34, 568 (1895).

${ }^{2}$ U. S. Dept. Agr., Bureau of Chem., Bull. 54.

3 Analyst, 22, 258 ( 1897 ).

4 Z. anal. Chem. 39, 545 (1900).

${ }^{5}$ U. S. Dep't. Agr., Burean of Chem., Bull. 73.

${ }^{6}$ Ibid., Bull. 8I.

7 Ibid., Bull. go. 
sults that were more nearly correct, or at any rate relatively constant. As a result of this work it was found that much more satisfactory and more constant results were obtained by increasing both the tannin content and the salt content of the reagent. Further particulars of our study of the method are given later.

COMPARISONS OF THE ACTION OF REAGENTS ON MEAT BASES.

Solutions of a number of simple amino bodies were treated with phosphotungstic acid in hot and cold solutions; with the tanninsalt reagent of the strength previously employed by the writers; and also a stronger tannin salt solution which was found to give more complete precipitation of the proteid bodies. The results of this work are given in Table I.

By consulting Table I it will be seen that with the more dilute tannin salt solution, precipitates were obtained with creatine, trimethylamine and phenylenediamine. These results were confirmed with the stronger solution of tannin salt, except that no precipitate was given with trimethylamine when the stronger solution was used. The weaker solution also gave a slight turbidity, but insufficient to indicate the precipitation of a determinable amount of nitrogen with glycocoll, alanine, glutamic acid, creatine and glutamine. It is probable that failure to obtain this turbidity with the stronger tannin salt solution is due to the increased difficulty of detecting a turbidity in that solution, and not to the solvent action of the stronger solution on the slight amount of material precipitated by the more dilute solution. Considering the fact that this turbidity was not detected in the stronger solution, and therefore at least was not increased by increasing the strength of the reagent, it is suggested that this was due not to the insolubility of the amino bodies in question in the presence of the tannin salt solution, but rather to a small amount of impurity contained in the preparations examined. It is apparent, however, that creatine and phenylenediamine cannot be separated by this method from peptones. In the case of creatine this is a serious matter, since that substance is the meat base which occurs most abundantly in meat and meat extract.

The error due to creatine, however, can be eliminated by determining the amount of creatine present before and after the pre- 

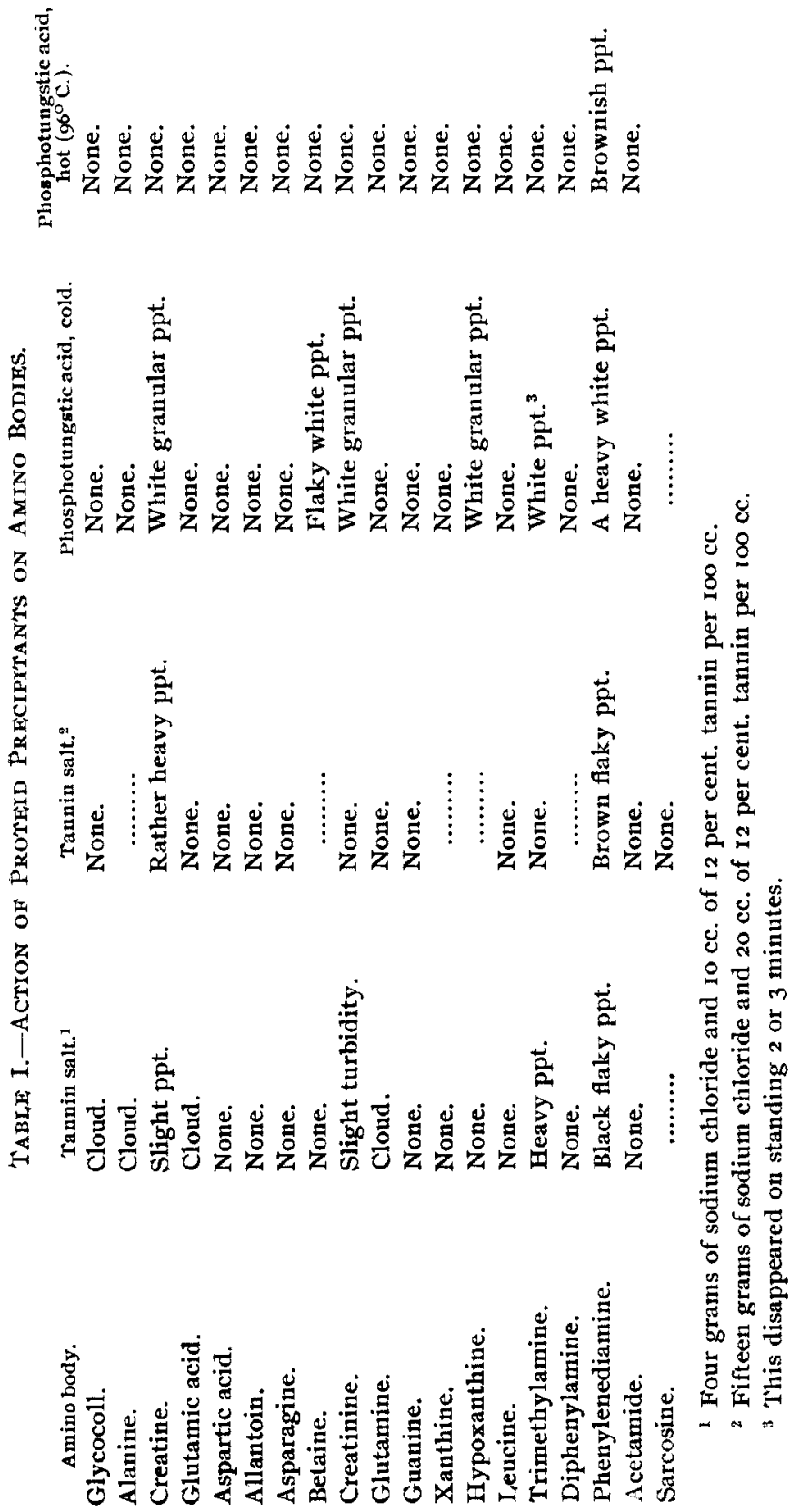
cipitation with the tannin salt reagent. The method for this determination is described below. It is believed that phenylenediamine does not occur in meat extract, and that in the examination of meat products, the fact that this substance is precipitated by the tannin salt reagent may be distegarded.

Mixtures of the amino bodies mentioned above were also treated with the same reagents except that in this case the stronger tannin salt solution was not employed, the work having been completed and our samples of amino bodies exhausted before our results indicating the advisability of using the stronger tannin salt solution were obtained. The results obtained by treating the mixtures of amino bodies with the reagents mentioned, as given in Table II, confirm those obtained with the unmixed solutions.

Table II - Action of Proteid Precipitants on Mixtures of Amino BODIES.

\begin{tabular}{|c|c|c|c|}
\hline \multirow{3}{*}{$\begin{array}{l}\text { Amino bodies. } \\
\text { Leucine } \\
\text { Gly cocoll }\end{array}$} & \multirow{3}{*}{$\begin{array}{l}\text { Tannin salt. }{ }^{1} \\
\text { Very s } 1 \mathrm{ig} \mathrm{h} \mathrm{t} \\
\text { cloud. }\end{array}$} & \multicolumn{2}{|c|}{ Phosphotungstic acid. } \\
\hline & & cold. & Hot $\left(96^{\circ} \mathrm{C}\right)$. \\
\hline & & None. & None. \\
\hline $\begin{array}{l}\text { Aspartic \& glu- } \\
\text { tamic acid. }\end{array}$ & Slight cloud. & None. & None. \\
\hline $\begin{array}{l}\text { Acetamide } \\
\text { Betaine }\end{array}$ & None. & None. & None. \\
\hline Creatine & Slight cloud. & Heavy white ppt. & None. \\
\hline $\begin{array}{l}\text { Allantoin } \\
\text { Asparagine }\end{array}$ & ne. & None. & None. \\
\hline $\begin{array}{l}\text { Xanthine } \\
\text { Hypoxanthine }\end{array}$ & f Faint cloud. & Heavy white ppt. & Slight ppt. \\
\hline $\begin{array}{l}\text { Guanine } \\
\text { Glutamine }\end{array}$ & \} None. & None. & None. \\
\hline
\end{tabular}

Trimethylamine
Diphenylamine $\begin{gathered}\text { Heavy yellow } \\ \text { brown ppt. Granular white ppt. Granular white ppt. }\end{gathered}$

Mixtures were then prepared of two commercial productsWitte's peptone and somatose-consisting largely of proteoses and peptones-with a number of the simple amino bodies, and treated with the reagents mentioned above. The nitrogen was determined in all solutions from which these mixtures were prepared, and the amount of nitrogen contained in the proteose or peptone body and in the simple amino bodies, as well as the

1 Four grams of sodium chloride and Io cc. of 12 per cent. tanuin per $100 \mathrm{cc}$. 
amount of nitrogen precipitated by the reagent employed, are given in Table III.

Table III.-Nitrogen Precipitated by Phosphotungstic acid and ZiNC SULPHATE FROM M TXTURES OF WITTE'S PEPTONE OR SOMATOSE, AND AMINo BOdies.

Nitrogen contained and determined.

Nitrogen content of Witte's
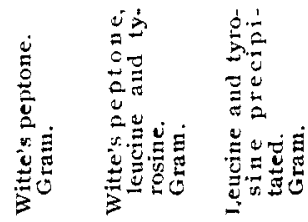

peptone or somatose ...0.0714

Nitrogen content of solution

of amino bodies.

Nitrogen precipitated by phosphotungstic acid. . . . 0.0655

Nitrogen precipitated by zinc sulphate. . . . . . 0.0404

$$
0.0407
$$

0.0003

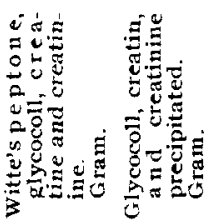

0.0762

0.0762

$0.0171 \quad \ldots \ldots$

$\ldots .0 .017$
0.0498

$\begin{array}{lll}0.0695 & 0.0790 & 0.0095\end{array}$
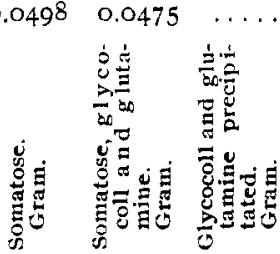

Nitrogen content of Witte's
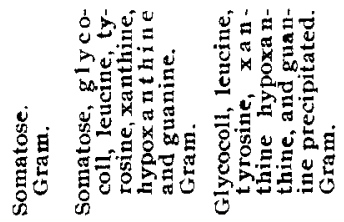

$0.0619 \quad 0.0619$

peptone or somatose ...0.06I9 0.0619

$\ldots \ldots$

0.0129

of amino bodies.......... 0.0106

Nitrogen precipitated by

$\begin{array}{llllll}\text { phosphotungstic acid ....0.0594 } & 0.0637 & 0.0043 & 0.0585 & 0.0604 & 0.0019\end{array}$

Nitrogen precipitated by zinc sulphate......... $0.0545 \quad 0.0547 \quad 0.0002$

The amount of nitrogen in the portion of Witte's peptone solution taken for examination was $0.07 \mathrm{I} 4 \mathrm{gram}$. Of this amount phosphotungstic acid (Stutzer's method) was found to precipitate 0.0655 gram, and zinc sulphate precipitated 0.0404 gram. To a similar portion of the solution of Witte's peptone was added a solution of leucine and tyrosine containing 0.0045 gram of nitrogen. Of this mixture phosphotungstic acid precipitated 0.0683 gram of nitrogen, and zinc sulphate precipitated 0.0407 gram of nitrogen. The precipitate obtained with zinc sulphate indicates that about two-thirds of the nitrogen present in this sample consisted of

1 Leucine 0.0025 gram and tyrosine 0.0020 gram. 
proteoses. Practically all of the remaining third is probably peptones. By deducting 0.0655 from 0.0683 the amount of nitrogen in the form of leucine and tyrosine precipitated by phosphotungstic acid is given as 0.0028 gram. The results given in this table appear to confirm the qualitative results given in Tables I and II.

ACTION OF TANNIN SALT REAGENT ON MEAT BASES IN THE PRESENCE OF PROTEOSES AND PEPTONES.

The tannin salt reagent was not included in Table III as at the time the work forming the basis of that table was done we had not satisfied ourselves with regard to the conditions under which the method could best be conducted. Similar work with the tannin salt reagent was repeated at a later time, and the results are given in Table IV.

Table IV.-Nitrogen Precipitated from Mixtures of Somatose and Meat Bases by Tannin Salt Reagent. ${ }^{2}$

\begin{tabular}{|c|c|c|c|}
\hline $\begin{array}{l}\text { Nitrogen in } \\
\text { somatose used. } \\
\text { Grams. }\end{array}$ & $\begin{array}{l}\text { Nitrogen } \\
\text { in amino } \\
\text { bodies used. } \\
\text { Grams. }\end{array}$ & $\begin{array}{c}\text { Total } \\
\text { nitrogen } \\
\text { precipitated. } \\
\text { Gram. }\end{array}$ & $\begin{array}{c}\text { Amino } \\
\text { nitrogen } \\
\text { precipitated. } \\
\text { Gram. }\end{array}$ \\
\hline$\ldots 0.1006$ & none & 0.0966 & none \\
\hline Phenylenediamine . . 0.1006 & 0.0230 & 0.1040 & 0.0074 \\
\hline Creatine ......... 0.1006 & 0.0494 & 0.1080 & 0.0114 \\
\hline Creatinine ....... o. 1006 & 0.0090 & 0.0984 & 0.0018 \\
\hline Glycocoll ........ o. 1006 & 0.0202 & 0.0966 & none \\
\hline Sarcosine ........ 0.1066 & 0.0270 & 0.0956 & -0.0010 \\
\hline Allantoin . . . . . . o. 0.1006 & 0.0348 & 0.0994 & 0.0028 \\
\hline Leucine.......... 0.1006 & 0.0034 & 0.0966 & none \\
\hline
\end{tabular}

Quantities of 0.8 gram each of somatose were mixed with several of the more important meat bases, and the nitrogen determined in the material precipitated by the tannin salt reagent from the mixture. The reagent employed for this purpose was the stronger solution mentioned above; that is, it contained ro grams of sodium chloride and 4 grams of tannin per roo cc. of the solution in which the precipitation occurs. The temperature was $12^{\circ} \mathrm{C}$.

It will be seen that in only two cases was an appreciable quantity of nitrogen obtained in the precipitate in excess of that obtained with the somatose alone. In the presence of phenylenediamine this was equal to 0.0074 gram of nitrogen, or about one-third

1 Reagent employed contained to grams of sodium chloride and 4 grams of tannin per roo cc. of the solution in which the precipitation occurred. The temperature was at $12^{\circ} \mathrm{C}$. 
of the amount present in the amino body. In the presence of creatine containing 0.0494 gram of nitrogen, a little less than one-fourth of that amount, or o.oI 44 gram of nitrogen was precipitated by the reagent. In the case of the other amino bodies studied the nitrogen in the precipitate from the tannin salt reagent was so nearly equal to that of the blank that it may be ignored as due to inaccuracies of the method.

\section{NITROGEN PRECIPITATED BY VARYING QUANTITIES OF SALT AND TANNIN.}

In the presence of a considerable amount of precipitable matter it is impracticable to determine with accuracy the quantity of reagent necessary to make precipitation complete. The amount of reagent was accordingly varied through wide limits for the purpose of determining the amount with which the most complete precipitation of proteid bodies could be obtained. It was found that by increasing the salt solution, even at a concentration far below that at which the precipitation of the ordinary proteids with sodium chloride occurs, the amount of nitrogen precipitated by the tannin salt solution was largely increased. It was also found that a corresponding increase of the precipitate was obtained by increasing the amount of tannin in the solution.

The varying results obtained with different strengths of sodium chloride and tannin suggested the advisability of determining whether there was any degree of concentration for both salt and tannin at which slight changes in concentration would be without material influence upon the results. To determine this the amount of nitrogen precipitated by the tannin salt reagent was determined in solutions whose sodium chloride content varied from 0.8 to 26 grams per $100 \mathrm{cc}$, and whose tannin content varied from 1.25 to 10 grams per $100 \mathrm{cc}$.

An inquiry of this sort is greatly complicated, owing to the fact that pure solutions of the proteid bodies can not be obtained. We have found it necessary to study those conditions which would give the maximum results with as pure solutions as were obtainable of proteoses and peptones, and then to use under such conditions solutions of the various meat bases in order to determine whether the latter were precipitated thereby.

An inspection of Tables V and VI will show that approximately the maximum results were obtained by using about 15 grams 
per Ioo cc. of sodium chloride and 4 or 5 grams per $100 \mathrm{cc}$. of tannin; that is, the proteid bodies under examination are dissolved in a small amount of water and concentrated solutions of sodium chloride and tannin added in sufficient amount to form solutions of the concentration given above. It also appears from Tables $V$ and VI that a considerable excess of tannin may be employed without any tendency of the reagent to dissolve the precipitate formed in excess.

It is, of course, impossible to determine how completely peptones are precipitated by the tannin salt reagent. It is interesting to know, however, that 15 grams of sodium chloride and 4 or 5 grams of tannin per $100 \mathrm{cc}$. of solution, which gives the maximum precipitation of proteids, precipitates from 96 to 98 per cent. of the total nitrogen contained in somatose, which from the nature of its preparation is supposed to consist largely of albumoses with a small amount of peptone. With the same reagent we precipitated about 94 per cent. of the total nitrogen contained in Witte's peptone, which is also supposed to consist chiefly of albumoses and peptones, but to contain a larger percentage of peptones than is found in somatose.

It thus appears that maximum precipitations of proteoses and peptones can be obtained from these substances with tannic acid and sodium chloride in the proportion of from 4 to 5 grams of the former and 15 grams of the latter per roo $\mathrm{cc}$. of the solution in which the precipitation is effected. This, taken into consideration with the fact that minimum precipitations are produced by this reagent with the meat bases, indicates that satisfactory results may be obtained with the reagent.

\section{EFFECT OF TEMPERATURE ON PRECIPITATION.}

Aliquot portions of solutions containing proteoses, peptones, and simple amino bodies were precipitated with the tannin salt reagent at three temperatures:

First, in a refrigerator at about $12^{\circ} \mathrm{C}$.

Second, at room temperature, the precipitate standing over night at about $23^{\circ} \mathrm{C}$.

Third, in a drying oven heated with a thermostat, the temperature regulated at about $40^{\circ} \mathrm{C}$.

It was found that higher results were obtained with a lower temperature and that the nitrogen precipitated at room tem- 
Table VI.-Amotist of Nitrogen Precipitated from I Gram of Somatose (Total Nitrogen =0.2149 Gram) by Varying Amounts of TanNin and Salt.

[Temperature $12^{\circ} \mathrm{C}$; total volume too cc.]

\begin{tabular}{|c|c|c|c|c|c|c|c|c|c|c|c|}
\hline \multirow[b]{2}{*}{$\begin{array}{l}\text { Sodium } \\
\text { chlotide } \\
\text { per joo cc. } \\
\text { Crams. }\end{array}$} & \multicolumn{11}{|c|}{ Grams of tannin in varying amounts of 12 per cent. solution used. } \\
\hline & $\begin{array}{c}\text { 10 ce. }= \\
\text { I.25 } \\
\text { grams. } \\
\text { Gram. }\end{array}$ & $\begin{array}{c}\text { I5 } \mathrm{cc}_{.}= \\
\text {I. } 87 \\
\text { grams. } \\
\text { Gram. } \\
0.1081\end{array}$ & $\begin{array}{c}20 \mathrm{cc} .= \\
2.50 \\
\text { grams.1 } \\
\text { Gram. } \\
0.1086\end{array}$ & $\begin{array}{c}25 \mathrm{cc}= \\
3.22 \\
\text { grams. } \\
\text { Gram. } \\
\ldots \ldots\end{array}$ & $\begin{array}{c}30 \mathrm{cc}= \\
3.75 \\
\text { grams. } \\
\text { Gram. } \\
0.1092\end{array}$ & $\begin{array}{c}35 \text { cc. }= \\
4.37 \\
\text { grams. } \\
\text { Gram. }\end{array}$ & $\begin{array}{l}40 \mathrm{cc},= \\
5.00 \\
\text { grams. } \\
\text { Gram. }\end{array}$ & $\begin{array}{c}50 \mathrm{cc},= \\
6,25 \\
\text { grams. } \\
\text { Gram. }\end{array}$ & $\begin{array}{c}60 \text { cc. }= \\
7.50 \\
\text { grams. } \\
\text { Gram. }\end{array}$ & $\begin{array}{l}70 \mathrm{cc} .= \\
8.75 \\
\text { grams. } \\
\text { Gram. }\end{array}$ & $\begin{array}{l}80 \mathrm{cc},= \\
10,00 \\
\text { grams. } \\
\text { Gram. }\end{array}$ \\
\hline $0,8 \ldots$ & 0.1014 & $\left\{\begin{array}{l}\text { O.IIII } \\
\text { O. }\end{array}\right.$ & 0.1126 & $\ldots \ldots$ & $0.1552\}$ & $\ldots \ldots$ & $\cdots$ & $\cdots \cdots$ & ‥ & ‥ & ... \\
\hline I.0..... & ..... & $\ldots \ldots$ & $\ldots \ldots$ & $\ldots \ldots$ & $\ldots \ldots$ & $\ldots \ldots$ & $\ldots \ldots$ & o.I 167 & 0.1173 & $\ldots \ldots$ & 0.1157 \\
\hline $2.0 \ldots \ldots$ & $\ldots \ldots$ & 0.1036 & $\begin{array}{l}\ldots .5097 \\
0 .\end{array}$ & $\begin{array}{l}\ldots \ldots \\
\ldots \ldots\end{array}$ & $\ldots .1097$ & $\ldots \ldots$ & $\ldots$ & $\ldots \ldots$ & 0.1161 & 0.1167 & …… \\
\hline $4.0 \ldots \ldots$ & $\ldots \ldots$ & $\left\{\begin{array}{l}0.1063 \\
\text {. }\end{array}\right.$ & $0.1 \times 37$ & $\ldots \ldots$ & $0.1157\}$ & $\ldots \ldots$ & $\ldots \ldots$ & $\ldots \ldots$ & 0.1179 & 0.1179 & $\ldots \ldots$ \\
\hline $5.0 \ldots \ldots$ & 0.1036 & $\ldots \ldots$ & $\ldots \ldots$ & $\ldots \ldots$ & $\ldots \ldots$ & $\ldots \ldots$ & ...... lo & Wo. I I 27 & $\cdots \cdots$ & $\cdots \cdots$ & $\cdots \cdots$ \\
\hline $6.0 \ldots$ & $\ldots \ldots$ & $\ldots \ldots$ & $\ldots \ldots$ & $\ldots \ldots$ & O.1109 & $\cdots \cdots$ & $\ldots \cdots$ & $\ldots \ldots$ & 0.1179 & 0.1167 & $\ldots \ldots$ \\
\hline $7.0 \ldots \ldots$ & 0.1067 & 0.1133 & O. I I 49 & $\ldots \cdots$ & $\left\{\begin{array}{l}0.1169 \\
0.10\end{array}\right.$ & $\ldots \ldots$ & $\ldots \ldots$ & 0.1169 & $\cdots \cdots$ & $\cdots \cdot$ & $\cdots$ \\
\hline $8.0 \ldots \ldots$ & 0.1073 & 0.1127 & $\left\{\begin{array}{l}0.1114 \\
0.1 \mathrm{I} 49\end{array}\right\}$ & $\ldots \ldots$ & 0.1151 & $\ldots \ldots$ & $\ldots \ldots$ & 0.1141 & 0.1189 & 0.1185 & … \\
\hline $9.0 \ldots$. & 0.1070 & $\left\{\begin{array}{l}0.1109 \\
0.1139\end{array}\right.$ & $\ldots \ldots$ & $\cdots \cdots$ & $\cdots \cdots$ & $\cdots \cdots$ & $\ldots \ldots$ & $\cdots \cdots$ & $\cdots \cdots$ & $\cdots \cdot \cdot$ & $\cdots$ \\
\hline $10.0 \ldots \ldots$ & 0.1079 & O. I I 33 & $0.1 \leq 37$ & $\ldots \cdots$ & $\left\{\begin{array}{l}0.1120 \\
0.1151\end{array}\right.$ & $\ldots \ldots$ & $\begin{array}{l}\cdots \\
\ldots \ldots \\
\ldots\end{array}$ & $\begin{array}{l}0.1189 \\
0.1147\end{array}$ & $\left.\begin{array}{l}0.119 .5 \\
0.1207\end{array}\right\}$ & 0.1189 & 0.1207 \\
\hline $11.0 \ldots \ldots$ & $0 . \log _{3}$ & 0,1145 & $\begin{array}{l}0.1155 \\
0.1120\end{array}$ & $\ldots \ldots$ & 0.1163 & $\ldots \ldots$ & $\ldots \ldots$ & o. I I 53 & $\ldots \ldots$ & $\cdots \cdots$ & $\cdots \cdots$ \\
\hline $12.0 \ldots \ldots$ & O.IIOI & 0.1145 & $\{0,1160\}$ & $\ldots \ldots$ & 0.1163 & $\ldots \ldots$ & ...... & 0.1147 & 0.1207 & $\ldots \ldots$ & 0.12 I9 \\
\hline $13.0 \ldots \ldots$ & 0.1095 & $\left\{\begin{array}{l}0.1140 \\
0.1155\end{array}\right.$ & O. II 55 & $\ldots \ldots$ & 0.1169 & $\cdots \cdots$ & $\cdots \cdots$ & 0.1153 & $\ldots \ldots$ & $\cdots \cdots$ & $\cdots$ \\
\hline $14.0 \ldots \ldots$ & 0.1060 & 0.1125 & n... & $\ldots \ldots$ & 0.1192 & $\cdots \cdots$ & $\cdots \cdots$ & $\cdots \cdots$ & $\cdots \cdots$ & $\cdots \cdots$ & $\cdots \cdots$ \\
\hline $15.0 \ldots \ldots$ & 0.1095 & $0.1 I 49$ & $\left\{\begin{array}{l}0.1 \text { I } 88 \\
0.117 \text { I }\end{array}\right\}$ & 0.1191 & $\left\{\begin{array}{l}0.1199 \\
0.1175\end{array}\right\}$ & 0.1208 & $0.121 \mathrm{I}$ & $0.120^{\circ}$ & 0.1223 & 0.1223 & 0.1229 \\
\hline $16.0 \ldots \ldots$ & & & $\left\{\begin{array}{l}0.1125 \\
0.1165\end{array}\right\}$ & $\cdots \cdots$ & $\cdots \cdots$ & $\cdots \cdots$ & $\cdots \cdots \cdot$ & $\ldots$ & $\cdots \cdots$ & $\cdots \cdots$ & \\
\hline $17.0 \ldots \ldots$ & $\ldots \ldots$ & $\left\{\begin{array}{l}0.1125 \\
0.1155\end{array}\right.$ & 0.1188 & $0.119 I$ & 0.1199 & 0.1202 & 0.1205 & 0.1211 & $0.12 \mathrm{I} 2$ & 0.1207 & \\
\hline $18.0 \ldots \ldots$ & 0.1098 & $\ldots \ldots$ & $\cdots \cdots$ & $\cdots \cdots$ & $\cdots \cdots$ & $\cdots \cdots$ & $\cdots \cdots$ & $\cdots \cdots$ & $\cdots \cdots$ & $\cdots \cdots$ & $\cdots \cdots$ \\
\hline $20.0 \ldots .$. & 0.1148 & 0.1183 & $\left\{\begin{array}{l}0.1193 \\
0.1 \mathrm{I} 86\end{array}\right\}$ & $0 . \mathrm{IIgI}$ & $\left\{\begin{array}{l}0.1199 \\
0.1208\end{array}\right\}$ & 0.1202 & $\left\{\begin{array}{l}0.1219 \\
0.1217\end{array}\right.$ & $\left.\begin{array}{l}0.1217 \\
0.1212\end{array}\right\}$ & $\cdots \cdot$ & $\cdots \cdot \cdot$ & \\
\hline $23.0 \ldots \ldots$ & $\ldots$ & 0.1184 & $\left\{\begin{array}{l}0.1199 \\
0.1186\end{array}\right.$ & 0.1202 & $\left.9.1217^{2}\right\}$ & & ...... & $\cdots$ & $\cdots$ & & \\
\hline$\ldots$ & $\ldots \ldots$ & $\cdots \cdots$ & 0,1200 & $\cdots \cdots$ & $\cdots$ & $\cdots \cdots$ & $\cdots \cdots$ & $\cdots \cdots$ & $\cdots$ & $\cdots$ & \\
\hline $26.0 \ldots \ldots$ & & $\ldots \ldots$ & 0.1187 & $\cdots \cdots$ & $\cdots$ & $\ldots$ & $\ldots$ & $\cdots$ & $\cdots$ & $\ldots \ldots$ & $\cdots$ \\
\hline
\end{tabular}

"From the column headed " $20 \mathrm{cc."}$ on, in the majority of cases a 24 per cent. solution was diluted to one-half, the resulting strength being the sane as that indicated in the table.

2 Twenty-eight cc. of tannin used.

Nore-The figures in ordinary type are those of the regular series in which the nitrogen in the tannin solution used was undetermined. The figures in black-faced type do not belong to the regular series. In all of these cases the nitrogen in the tannin used was determined. The fact that these figures are lower than those of the regular series is due to the allowance made for the nitrogen in the tannin, as well as to the fact that a different lot of tannin was used. 

perature was greater in amount than that precipitated at $40^{\circ} \mathrm{C}$. Moreover, the lower the temperature, the clearer was the supernatant liquid and the more complete the precipitation. The supernatant liquid in the case of the precipitations made at $40^{\circ} \mathrm{C}$. was quite commonly turbid, and in many cases filtration was entirely impracticable. In the case of the precipitations made at room temperature the supernatant liquid, though usually clear, was occasionally turbid and filtration difficult. With the precipitations made in the refrigerator at a temperature of about $12^{\circ} \mathrm{C}$. the supernatant liquid was almost always clear and the filtrations (which were also conducted in the refrigerator) rapid and satisfactory, leaving a perfectly clear filtrate.

\section{COMPARISON OF VARIOUS TANNINS.}

Different samples of tannin do not give uniform results with a given mixture of proteids and meat bases. The difference in some cases is so great as to lead to considerable inaccuracy, and it is of course essential that a uniform tannin be used in the prosecution of any particular investigation. At the same time there has been nothing in our experience to indicate that this difference is so great as to preclude the practicability of comparing in a general way the work of different laboratories. The lack of uniformity is considerable, however, and impairs the value of such a comparison. The results of this study are given in Tables VII and VIII. One important consideration that appears to have been overlooked is the nitrogen content of tannin. As will be seen in Table VIII the amount of nitrogen contained

Table VII.-Comparison of the Precipitating Power of Two TanNINS ON I GRAM OF SOMATOSA IN THE PRESENCE OF

VARYING AMOUNTS OF SAIT.

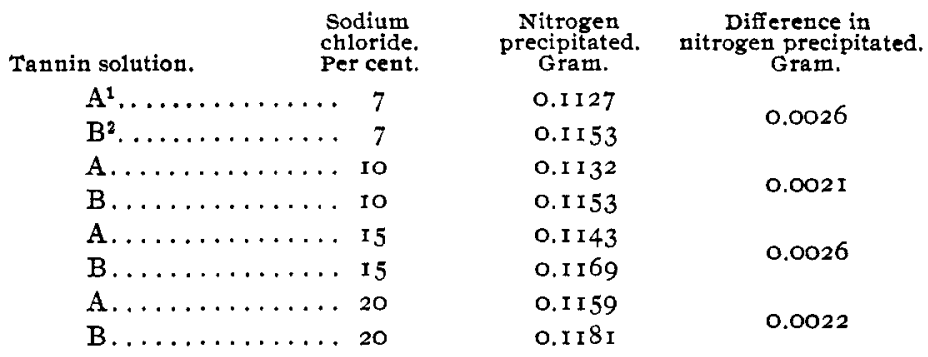

I Nitrogen per ro cc. $=0.0020$ gram.

2 Nitrogen per lo cc. $=0.0012$ gram. 
in some samples of tannin is considerable, and a correction must always be made. A varying amount of the nitrogen in the tannin is either insoluble in water, or is precipitated from a tannin solution by sodium chloride, and hence is insoluble in the tannin salt reagent. It is important that blanks be run with the reagents employed, and that a correction be made for the total nitrogen in the tannin employed as well as the nitrogen in the tannin insoluble in the tannin salt reagent.

In Table VIII are given the results of the influence of reagents prepared from three samples of tannin upon solutions of somatose. In all cases the volume of the liquid in which the precipitation occurred was roo cc., and contained 2.49 grams of tannin and Io grams of salt. In the three samples the amount of nitrogen varied from 0. I 55 to 0. I I 9 I gram. The nitrogen content of the tannin itself must also be taken into consideration. This is a factor which we have only recently considered in connection with this work, but the amount of nitrogen has been found so great that it should always be determined and a correction applied. The three samples mentioned were found to contain 0.0007 to 0.0052 gram of nitrogen in $20 \mathrm{cc}$. of the sample.

TABLE VIII. ${ }^{1}$-NITROGEN CONTENT AND COMPARISON OF PRECIPITATING POWER OF VARIOUS TANNINS.

\begin{tabular}{|c|c|c|c|}
\hline Reagent. & $\begin{array}{c}\text { Total } \\
\text { titrogen. } \\
\text { Gram. }\end{array}$ & $\begin{array}{c}\text { Nitrogen } \\
\text { precipitated. } \\
\text { Gram }\end{array}$ & $\begin{array}{l}\text { Nitrogen in } \\
\text { the } 2.49 \text { g tams } \\
\text { of tannin used. } \\
\text { Gram. }\end{array}$ \\
\hline No. I Tannin & 0.1249 & 0.1191 & 0.00068 \\
\hline No. 2 Tannin & 0.1249 & 0.1165 & 0.00112 \\
\hline No. 3 Tannin & 0.1249 & 0.1155 & $0.005^{2}$ \\
\hline No. 4 Tannin & 0.1249 & $\ldots \ldots$ & 0.0104 \\
\hline
\end{tabular}

To further study this question the nitrogen precipitate was obtained on quantities of I gram of somatose, using the tannin salt precipitate prepared from two of the above lots of tannin. The results are given in Table VII. In all cases the precipitations occurred in roo cc. of liquid, which contained I 2 grams of tannin and the amount of sodium chloride given in the table. It will be seen that the difference in precipitating power of the two tannins is of considerable magnitude. In all cases in both Tables VII and VIII the quantity of nitrogen contained in the tannin itself

${ }^{1}$ All tannin solutions were made 12 per cent. and $20 \mathrm{cc}$. used in each case. Ten grams of salt were also added and I gram of somatose used. Ice box temperature, $I 2^{\circ}$.

2 Corrected for uitrogen content of reagent. 
has been allowed for, and is not responsible for the difference shown in the precipitating power of the various tannins.

PRESERVATION OF TANNIN SALT REAGENT.

It is well known that tannin undergoes fermentation in solution and loses to a large extent its power of precipitating proteids. We have found that this occurs even in the presence of a considerable quantity of salt, and that the tannin salt reagent should be kept in a cool place, and should not stand more than a few days before using.

\section{DETAILED DESCRIPTION OF MODIFIED TANNIN SALT METHOD.}

One gram of meat powders, 2 grams of preparations of pasty consistency and from Io to $20 \mathrm{cc}$. of liquid or semiliquid extracts should be employed. Solid and pasty preparations are dissolved in a little cold water in a $100 \mathrm{cc}$. graduated flask, keeping the volume within $20 \mathrm{cc}$.

Then $50 \mathrm{cc}$. of a solution containing 30 grams of sodium chloride per $100 \mathrm{cc}$. are added and the flask agitated to insure the thorough mixing of its contents and the solution of the sample. The flask is now placed in the ice box at approximately $12^{\circ} \mathrm{C}$. After the solution has reached the ice box temperature (this requires an hour usually) $30 \mathrm{cc}$. of a 24 per cent. solution of tannin (which must be at ice box temperature) are added. The total volume is now diluted to Ioo cc. The contents of the flask are thoroughly mixed and the flask returned to the ice box, where it remains over night. In the morning the solution is filtered at ice box temperature into a $50 \mathrm{cc}$. graduated flask. The nitrogen is determined in this filtrate, and also in an aliquot portion of the filtrate from a blank, in which the reagents alone are employed. The nitrogen found in the $50 \mathrm{cc}$. portion multiplied by two (after correction for the nitrogen in the blank) gives the total nitrogen in the filtrate, and includes the nitrogen present as ammonia and all of the nitrogen of the meat bases except that portion of the creatine precipitated by the tannin salt reagent.

In the examination of products that contain insoluble or coagulable proteids, $20 \mathrm{cc}$. of the filtrate from the coagulable proteids are used for this determination. The volumes of the solution of the meat extract employed, and of the two reagents will then make Ioo $\mathrm{cc}$. and require no further dilution. The nitrogen thus precipitated by the tannin salt reagent (calculated 
by difference) consists of that present in the form of proteoses and peptones, and the peptone nitrogen may of course be found by deducting the proteose nitrogen, obtained by precipitation with zinc sulphate, from the total amount of nitrogen precipitated by the tannin salt reagent.

\section{DETERMINATION OF CREATINE AND CREATININE.}

It is stated above that the error occasioned by the precipitation of a portion of the creatine by the tannin salt reagent may be corrected by determining the creatine before the application of the tannin-salt reagent, and in the filtrate from the precipitate given by that reagent. At the suggestion of Prof. L. B. Mendel the method of Folin ${ }^{1}$ for the determination of creatine in urine was applied by us to the determination of creatine in meat extracts. Before applying the method it was of course necessary to convert the creatine present into creatinine by dehydrating with hydrochloric acid. As we have noted above, the tannin salt reagent precipitates a portion of the creatine in mixtures of albumoses, peptones and creatine. This is also the case in meat extracts and the proportion of creatine precipitated by the tannin salt reagent varies with each individual extract, as one would suppose. It was therefore necessary to determine the total creatinine (after dehydrating with hydrochloricacid) in the original sample, and also in the peptone filtrate, the difference being the creatine precipitated by the tannin salt reagent. In making the creatine determination on the original sample, a portion of the filtrate from the coagulable and insoluble proteids was employed. The amount used corresponded to about 2 grans of the original solid extract. In the case of the peptone filtrate some trouble was experienced, as the tannin which was present in large quantities interfered and it was necessary to remove it. The following method of procedure was consequently adopted:

From 40 to $50 \mathrm{cc}$. of the tannin salt filtrate was heated on the steam-bath with hydrochloric acid to convert all creatine to creatinine, $5 \mathrm{cc}$. of ro per cent. barium chloride solution were added and sodium hydroxide to distinct alkalinity. The contents of the flask were then thoroughly mixed by shaking, filtered, and the precipitate washed with water. From the filtrate and washings, which are now practically free from tannin, the excess of

1. Z. Physiol, Chem. ro, 39r, I886. 
barium is removed by precipitation with sulphuric acid, filtered, and the precipitate washed. The filtrate is now ready for the usual application of the creatine method. When very small quantities of creatine are present, the usual difficulties of reading are experienced, but in most cases the readings ran from $2 \mathrm{~mm}$. to I $2 \mathrm{~mm}$. on the Duboseq colorimeter. The percentage of peptones as determined is corrected by the figure thus obtained. It is of course necessary to determine ammonia in the original sample and make a correction therefore in the calculated percentage of peptones.

\section{THE PHOSPHORUS CONTENT OF FECES FAT. ${ }^{1}$}

BY J. H. L,ONG AND W. A. Johnson.

Received July I3, Igo6.

IN a recent communication ${ }^{2}$ attention was called byone of us to the high phosphorus content of the feces fat of a man in normal health, under conditions where, according to the usual statements in the literature, little or no phosphorus should be found. The phosphorus, in the form of phosphoric acid, obtained from feces fat, as extracted by perfectly dry ether, has always been assumed to have its origin in bodies of the lecithin type, and the detection and estimation of lecithin here have been made to depend on the recognition and determination of phosphoric acid among the products of decomposition of the fat.

However, that all the ether-soluble organic phosphorus obtained through the extraction of dried feces may be assumed to come from a lecithin body may well be doubted, in view of the many conflicting results obtained in the last few years in the examination of fresh animal and vegetable tissues as well as of feces. All the more recent investigations on the subject agree in suggesting that what has been called "lecithin" is evidently a mixture, and as a preliminary to the discussion of the nature of the phosphorus-containing bodies in the feces we have thought it well to make a new series of phosphorus, and also nitrogen determinations in the fat extracted under certain conditions.

In the paper cited above the method of extracting the fat was referred to. In the work below the same plans were followed,

1 Presented at the June ( 1906 ) meeting of the American Chemical Society at Ithaca.

2 Long: This Journal, 28, 704 . 